\title{
Л.Ш. Таштамирова
}

\section{ВЛИЯНИЕ МИФОТВОРЧЕСТВА Ф. НОВАЛИСА НА ТВОРЧЕСТВО Р. ВАГНЕРА. СРАВНИТЕЛЬНЫЙ АНАЛИЗ ПРОИЗВЕДЕНИЙ}

\begin{abstract}
В статье рассмотрены проблемы конструирования оперного либретто в творчестве P. Вагнера. Мифы, разворачивающиеся в операх Р. Вагнера, создают новый способ коммуникации со слушателем, основанный на обращении к бессознательному началу воспринимающей личности. Р. Вагнер комбинирует сюжетные мифологические мотивы, создавая собственную мифологию. Его новый миф базируется на мифах народных и религиозных, такой интертекстуальный синтез сюжетов создает пример нового типа авторской мифологии. Такой тип синтеза становится моделью мифотворчества для композиторов, писателей, кинематографистов, мыслителей не только ХІХ, но и ХХ в.

Ключевые слова: Р. Вагнер, Ф. Новалис, оперное либретто, новая мифология.
\end{abstract}

Проблема мифологии, изложенная Р. Вагнером в его литературных трудах, не исчерпывает всей проблемы понимания и использования композитором мифа. Либретто опер Р. Вагнера дают обширный материал для исследования. В исследовательской литературе остается открытым вопрос о проблемах конструирования новой мифологии в операх Р. Вагнера. При исследовании мы обнаружили взаимосвязь между литературными произведениями немецких романтиков В.Г. Вакенродера, Л. Тика, А.Ф. Арнима, К. Брентано и произведениями Р. Вагнера. Существенные аналогии возникают между либретто опер Р. Вагнера и «Сказкой Клингсора» из романа «Генрих фон Офтердинген» (1799) Ф. Новалиса. Мы считаем, что для Р. Вагнера это произведение послужило примером конструирования мифа в собственных произведениях. Художников сближало не только использование общих методов при построении и трактовке сюжета, но и общее понимание целей и задач искусства. Р. Вагнер и Ф. Новалис были поэтами, а не учеными или философами, которые придерживались научного подхода при создании произведения искусства. Они познавали мир через художественное восприятие, а не рационально-логическим путем. Таким образом, они создавали новый миф, который, по словам Ф. Шлегеля, «то, что вечно ускользало бы от сознания, удерживается здесь в чувственно-духовном созерцании, подобно тому, как душа благодаря облекающему ее телу доступна нашему взору и слуху» [1. С. 167]. Одной из самых существенных сторон эстетики Новалиса была мысль о взаимодействии творческого духа с процессом познания. В его представлении образ и понятие взаимно дополняют друг друга, возникая «мгновенно и одновременно». «В конечном итоге всякая поэзия - перевод», - писал он [2. С. 342]. Речь шла о переводе идеи в образ. Р. Вагнер в «Произведении искусства будущего» указывает на «образотворящую силу мысли в произведении искусства» [3. С. 116]. В его работах развита идея са- 
мопознающей духовной субстанции. Его теории имеют широкое философское обоснование. Так, Вагнер считает, что «природа самопознает себя в человеке, более того, человеческая жизнь строится по законам природы и копирует ее основные циклы. Человеческая жизнь, согласно воззрениям Вагнера, познает себя в науке, для которой она является объектом для исследований. Изображает постигнутую наукой жизнь - искусство, которое и есть окончательное выражение истины» [3. С. 109].

Характерной чертой немецкой литературной сказки и опер Р. Вагнера является то, что главные проблемы сказки лежат вне временной плоскости. Все главные герои сказок живут в условной действительности. Действие новалисовской сказки о Гиацинте и Розенблют происходит «далеко на западе», причем неизвестно, где начало отсчета, применительно к какому месту расположен этот «далекий» запад. Местом действия в сказке, как правило, является некое романтическое пространство, к художественному освоению которого были направлены устремления романтиков.

Время действия сказок тем более лишено определенности. У ранних романтиков оно вообще не обладает никакими историческими приметами. Более того, в своем историческом содержании оно, по сути, отвергается, хотя порой они ощущают привязанность к «колесу времени». «Святой» у Вакенродера считает эту связь мучительной и гнетущей. «Мифологическое сознание, - пишет Ю.М. Лотман, характеризуется замкнуто-циклическим отношением ко времени». Сказка утверждает вечные категории и стряхивает с себя все временное как единичное, несущественное, мешающее развитию «шестого чувства».

Р. Вагнер, основываясь на опыте немецких литераторов, также помещает своих героев во внепространственный и вневременной континуум. Конкретное историческое время можно определить с достаточной долей условности средневековье («Лоэнгрин», «Тристан и Изольда»), древний мир («Кольцо нибелунгов»). Более того, можно сделать вывод, о том, что всякая временная конкретизация невозможна, так как при ближайшем рассмотрении Тангейзер живет между двумя мирами - католическим, где существуют Папа, пилигримы, Елизавета, молящаяся в монастыре за душу Тангейзера и древнеримский грот Венеры, находящийся вне времени и пространства. Р. Вагнер, наполняя свои произведения новым трансцендентальным смыслом, расширяет способы сюжетообразования - он основывает свои либретто на конкретных мифах и легендах европейской цивилизации - мифология «Старшей Эрды» о нибелунгах, богах Валгаллы, валькириях; легенда о Тристане и Изольде, легенда о Летучем голландце и др. Р. Вагнер в своем творчестве разворачивает миф о рыцарях Круглого стола, который также находится в некоем параллельном времени и пространстве. Использование этого мифа, являющегося сакральным христианским символом, актуальным по сегодняшний день, наполняет произведения композитора не романтической фантастикой, но религиозной мистикой. Р. Вагнер, опираясь на конкретные легендарные и мифологические источники, сочетая их с приемом трансцендентной трактовки сюжета, достигает в своих произведениях нового качества - опора оперных сюжетов на архетипы, найденные западноевропейской культурой. В результате композитор превосходит достижения литературного романтизма на пути создания новой 
мифологии. Мифы, разворачивающиеся в операх Р. Вагнера, создают новый способ коммуникации со слушателем, основанный на обращении к бессознательному началу воспринимающей личности. Такой тип коммуникации основывается не на прямом вербальном контакте, а на общении через актуализацию культурных архетипов и культурной памяти воспринимающей стороны.

В трактовке мифопоэтического сюжета можно обнаружить аналогии между тетралогией Р. Вагнера и сказками Ф. Новалиса и скандинавскими мифами. Так, процесс развития мира в «Сказке Клингсора» выражен своеобразной триадой: «1) бессознательно-хаотическая гармония; 2) дисгармония исторического времени; 3) соединение природы и духа в будущем золотом веке» [2. С. 107]. Мысль двух художников не исторична, а метафизична. «Первоначальный мир» в их представлении менее всего связан с какой-либо исторической эпохой - античностью или средневековьем. Прабытие для обоих - некая абстрактная первозданность, идеальное состояние первого дня творения. В одном из фрагментов оно обозначено как «время до мира». В подобном разделении миров в мифе Р. Вагнера и Ф. Новалиса нашли свое отражение романтическая эсхатология и романтические надежды на обновление мира. Традиционная сказочная схема в сказке Ф. Новалиса преображается. Дочь короля Арктура - Фрея - подобно спящей красавице, должна быть избавлена от чар и пробуждена к новой жизни своим суженым Эротом. Когда он запечатлевает на ее устах поцелуй, снимаются тяготы времени и наступает «золотой век». История маленькой Фабель отдаленно напоминает злоключения сказочной падчерицы. Практически во всех операх Р. Вагнера можно отметить подобную смысловую направленность в разворачивании сюжета. Летучий голландец, совершив преступления в дисгармоничном прошлом, ищет путей прощения грехов в дисгармоничном, бесконечном настоящем времени и обретает покой, достигая собственного золотого века. Сюжет тетралогии «Кольцо нибелунгов» наиболее близок схеме, в котором герои двигаются от хаотичного, смутного прошлого через запутанное настоящее к золотому веку: желание Альбериха обладать властью над миром, его отречение от любви приводит к гибели богов. Сюжет тетралогии, сохраняя общее направление от хаоса к свету, получает под пером Р. Вагнера некоторые структурные особенности. В опере «Золото Рейна» разворачиваются события прошлого, послужившие источником дисгармонии настоящего. Одновременно с этим эти события разворачиваются в настоящем времени и показывают зрителю картину первобытной гармонии. Действие начинается в золотом веке, показывается потеря и отход от первоначальной гармонии, а затем сюжет разворачивается в направлении обретения счастливого будущего. Подобная трактовка времени является по своей сути еще одним архетипом, в данном случае универсальном способе трактовки происходящих событий, свойственном каждому человеку. Р. Вагнер, таким образом, соединяет в развитии сюжета три времени - прошлое, настоящее и будущее. Подобным образом построен сюжет и в остальных трех операх тетралогии. При этом следует отметить еще одну особенность - реальные действия тесно переплетены с рассказами о событиях прошлого. Более того, можно сказать, что рассказы о прошлом перевешивают реально проходящие действия на сцене. Эта монологичная и диа- 
логичная структура изложения характерна и для сюжетного построения народных мифов, и для способов изложения сюжета в романах немецких романтических писателей.

Сходна и вертикальная сюжетная ось в организации сюжета в «Сказке Клингсора» Ф. Новалиса и в тетралогии Р. Вагнера. Место действия - космос. Время прошедшего действия - вся человеческая история в совокупности ее настоящего и будущего. По Ф. Новалису, искусство и не должно основываться на подражании жизни. «Поэзия, - считает он, - являет собой нечто прямо противоположное. Подражание природе, действительности в крайнем случае время от времени может использоваться либо только аллегорически, либо для достижения трагического или веселого эффекта» [2]. В «Сказке Клингсора», в отличие от других сказок Новалиса, отклонение от жизнеподобия максимально. Вселенская структура предстает в виде четырех соединяющихся, но по-своему автономных миров: царство Арктура, через мир «дома» соединенное с подземным пространством, где обитают Парки, и обособленное от всего прочего царство Месяца. Таковы места действия, где работают созидательные и разрушительные силы вселенной. Ее мифологические обитатели Мать, Отец, София, Джиннистан, Эрос, Фабель, Писец - олицетворяют силовые линии новалисовской космогонии. В событиях, разворачивающихся в тетралогии Р. Вагнера, можно усмотреть разделение на четыре мира. Однако они разделены в соответствии с традициями скандинавской мифологии. Мир гномов, мир людей, мир богов - Валгалла, мир богини судьбы Эрды, находящийся в земных недрах, в подземном мире находятся норны, богини, плетущие нити судеб мира и людей. Соединяющим звеном между мирами становится Вотан, который создает род Вельзунгов в мире людей, из которого родом Зигмунд и Зиглинда, Зигфрид, - его дети. В мире богов существуют Валькирии - дочери Вотана и Эрды. Валькирии Брунгильде и Зигфриду Вотан предназначает роль спасителей мира. В других операх Р. Вагнера двухуровневое строение мира - мир богов и мир людей. Мир богов чаще всего предстает в виде братства Св. Грааля, находящегося в пространстве между мирами. Он занимает промежуточное положение между высшим миром, который недоступен человеческому пониманию, о нем можно судить по расцветшему посоху Тангейзера или силам, покаравшим Летучего голландца. Использование традиционного для мифов разделения миров знакомо и свойственно большому количеству людей. Поэтому восприятие сюжета, основанное на закономерностях массового сознания, становится доступным и понятным широкому кругу слушателей, возможно, на интуитивном уровне.

Одинаковы концепции двух произведений: погрязший в грехах мир должен возродиться с помощью любви и поэзии, через череду жертв и трагедий. Р. Вагнер актуализирует еще один миф - противопоставление жажды власти и любви. Тема, до него не обсуждаемая в оперных произведениях. Она становится особенно важной в условиях новой революционной реальности Германии и Европы. Именно он дает простор режиссерам при постановке опер Р. Вагнера, когда Вотан появляется на сцене в одежде красного комиссара, а нибелунги предстают в виде рабочих на некоем предприятии. Р. Вагнер в тетралогии открывает новый мир скандинавской мифологии, который будет 
популярным во второй половине XX в. - в трилогии Дж. Р.Р. Толкиена и в кинематографической саге «Властелин колец».

Центральный персонаж сказки - ищущий герой. Герой сказки изначально оказывался поставленным в некие идеальные, почти лабораторные условия. Явления внешнего мира могли быть дружественны или враждебны к нему, он все равно оказывался в мире чистых сущностей, в мире, принципиально воспринимаемом им как некое мифологическое единство. Поэтому история героя всегда имеет «начало» и «конец», она полностью завершена на мифологическом уровне. Утверждаемый романтиками принцип фрагментарности в художественном творчестве не коснулся сказки именно в силу особой направленности этого жанра, его притязаний на охват всеобъемлющих законов бытия. В тетралогии Р. Вагнера этим требованиям отвечает Зигфрид. Он с самого начала недоволен окружающей действительностью. Несмотря на то, что его воспитал гном Альберих, Зигфрид предчувствует свое предназначение, и как только начинаются разворачиваться события, для реализации которых он был рожден, Зигфрид без малейшего сожаления покидает «отчий дом», ведомый велениями судьбы. Он находится вне привычных представлений о поведении любящего сына. Зигфрид убивает Альбериха, не мучаясь при этом размышлениями о нравственности своего поступка, - он является «слепым орудием» внеличностных сил, выполняя свою функцию в продвижении сюжета.

Причем именно «концу» - финальным поискам ищущего героя - придается особое значение. Он - центр тяжести, к которому стремится фабульная основа сказки, ее итог. Дальнейшее движение судьбы героя сказкой изначально исключается. Завершенность сказочной композиции указывает на законченность концепции мироздания в сознании художника-творца. Он создает миф. Сюжет тетралогии не затрагивает жизнь героев до момента выполнения основной сюжетной функции. Герои живут как бы в пустом пространстве. Все, что было до этого, обладает нулевым значением. О жизни Зигмунда и Зиглинды мы узнаем из рассказов Вотана, Хагена.

Центральный персонаж сказки - всегда подвижный герой. Он носитель событийной стороны повествования, ибо только ему одному дозволено, говоря словами Ю.М. Лотмана, перемещение «через границу семантического поля». В этом его сюжетная функция. Вспомним путешествие Гиацинта в поисках «матери всех вещей» или образовательное странствование Генриха фон Офтердингена у Ф. Новалиса, бегство Берты из родного дома, а затем и из лесной хижины у Тика, блуждания Христиана с гор в долину и обратно в его же «Руненберге» или метания гофмановского Ансельма между миром повседневности и царством грез. В операх Р. Вагнера таким персонажем становится Парсифаль. Он один из немногих людей смог переместиться в мир братства Св. Грааля. Путь в мир братства напоминает миф о контактах людей с эльфами - внезапное перемещение и внезапный выход из царства эльфов.

Герой сказки не закреплен в едином пространственном континууме и в этом смысле наделен правом на особое поведение. На раннем этапе развития жанра он совершенно свободен. В сказках Новалиса, Вакенродера или Тика внешние препятствия для его движения отсутствуют. Предметное оформление сказки призвано выразить лишь движение или состояние созна- 
ния героя. Сюжетный поворот, «переход через границу семантического поля» здесь выступает в самом чистом виде как приключение в сфере духа. Для Гиацинта - это открытие под покрывалом Изиды своей любимой Розенблют как познание мира через любовь. Для вакенродеровского героя - отрешение от колеса времени и вознесение в дольные сферы чистого духа. Зигфрид совершает путешествие по Рейну. В этом путешествии соединены мифические представления о похоронных обрядах, связанных с водой. Зигфрид, путешествуя по реке, движется скорее не в географическом, а в духовном направлении.

Сказочный герой чаще всего исключен из сферы общественного бытия. Он жаждет познания, каждый раз устремляясь из обыденности или стесненности домашней жизни в другой мир. Иногда он обретает истину, а порой приходит к осознанию неразрешимой загадки мира. Таковыми являются практически все герои опер Р. Вагнера. Если Тангейзер имеет «профессиональное» прошлое, то Парсифаль, Зигфрид, Зигмунд не имеют ни социальнообщественных привязок, ни психологических характеристик.

Время может иметь движение, но не иметь развития. Чаще всего читателю открываются реалии вечной природы: горы, вздымающиеся в небо, облака, сменяющие друг друга в причудливом рисунке. Высятся леса, открываются взору реки и ручьи, долины и рощи. Человек оказывается в бескрайности универсума. В операх Р. Вагнера картины природы играют важную драматургическую роль. Сцены шелеста лес» из «Зигфрида», вступление к опере «Золота Рейна», рисующее катящиеся волны вечного Рейна, сцена заклинания огня из «Валькирий», сцена полета Валькирий, разворачивающаяся на фоне мрачных скал, - прямо отражают и особенности строения мифологического сюжета, и натурфилософские воззрения Р. Вагнера.

Композитор почерпнул из произведений Ф. Новалиса метод работы с мифологическим сюжетом, а также тематику, сюжетные мотивы, которые он позднее будет использовать в своих операх. Влияние Ф. Новалиса можно отнести, прежде всего, к тетралогии «Кольцо нибелунгов», а также к произведениям, в которых присутствуют сюжетные мотивы из католической мифологии - «Парсифаль», «Лоэнгрин», а если говорить о методе трактовки сюжета, то и ко всем произведениям Вагнера.

К другому уровню влияния Ф. Новалиса на творчество Р. Вагнера следует отнести наличие близких по имени и образу героев, трактовку мифологического сюжета, и их функционирование в сюжете. Так, например, проведение аналогий можно начать со сходства имен главных героев и их функционирование в сюжете. Так, один из героев сказки Ф. Новалиса - злой волшебник Клингсор близок образу Клингзора из оперы «Парсифаль» Р. Вагнера. Образ чувственной Фреи из сказки Ф. Новалиса схож с образом богини молодости Фреи из тетралогии Р. Вагнера. Одного из своих героев Ф. Новалис называет королем Арктуром, его имя восходит к названию самой яркой звезды Северного полушария (из созвездия Волопаса) и по звучанию напоминает имя легендарного короля Артура из кельтских сказаний. Р. Вагнер в операх «Лоэнгрин», «Парсифаль» использует образ короля Артура из средневековых рыцарских романов. Здесь следует отметить общую для двух художников трактовку образов Клингсора-Клингзора и короля Арктура-Артура. Оба дей- 
ствующих лица не принимают активного участия в развитии сюжета. Клингсор из сказки Ф. Новалиса - владыка некоего царства зла, но реализатором сюжетной линии и участницей конфликта является Фабель. В опере Р. Вагнера «Парсифаль» Клингзор не вступает в бой с Парсифалем, конфликт разрешает Кундри. Роль короля Арктура в сказке Ф. Новалиса также статична его царство является символическим изображением мира людей. Король Артур в операх Р. Вагнера не присутствует в виде реального персонажа. Его имя возникает в связи с использованием сюжетных мотивов из цикла легенд из кельтской мифологии. Р. Вагнер не использует легенды, напрямую связанные с жизнью короля Артура. Король Артур - циклообразующий персонаж в операх Вагнера. Так, Лоэнгрин (сын Парсифаля) и Парсифаль (Персифаль) были рыцарями Круглого стола. К циклу артуровских легенд примыкает такой миф, как «Тристан и Изольда». Их история представляет собой один из вариантов стержневого драматического сюжета истории короля Артура. Адюльтер его супруги Джиневры и самого выдающегося из всех рыцарей Ланселота в итоге привел к гибели всех персонажей. Главным же идеологическим сюжетом цикла артуровских легенд являются поиски рыцарями Круглого стола чаши под названием Священный Грааль. Все содержание либретто оперымистерии «Парсифаль» строится вокруг идеи обретения Св. Чаши.

Следующей общей чертой в конструировании мифа в произведениях Ф.Новалиса и Р. Вагнера является прием олицетворения. Так, герои Эридан, Железо и Цинк из сказки Ф. Новалиса олицетворяют реки и металлы. Мифологический образ обретают и светила (Месяц). Это открытие сказок Новалиса проистекает из соединения поэзии с философией. Знакомые предметы преображены, сущностные категории персонифицированы. Вещи и явления выступают в неожиданных сочетаниях. Мифопоэтическое мышление художника «опредмечивает» духовные субстанции. И поэтому в сказке Ф. Новалиса рядом с оледеневшей струей фонтана и снежными цветами замерзшего города появляется зеленый венок. В операх Р. Вагнера также использован прием персонификации предметов и стихий. Так, Логе - бог огня из тетралогии Р. Вагнера, предстает то в образе человека, то в образе огненной стихии. Такого рода образы едва ли могут исчерпываться рациональным толкованием. Мысль растворена в образе и существует по его законам. Она практически отождествляется с образом, становясь многозначным и до конца не подлежащим расшифровке символом. Таково свойство мифологического мышления. В этом случае сложно говорить о заимствованиях какого-либо рода. Возможно, следует говорить о том, что произведение Ф. Новалиса «дало» определенное направление для развития поэтической фантазии Р. Вагнера при создании образов или выборе сюжетных мифологических источников.

К другому приему конструирования мифов в произведениях Ф. Новалиса и операх Р. Вагнера можно отнести использование магических атрибутов в качестве сюжетообразующей линии. К ним можно отнести сюжетный мотив с использованием таких атрибуто,в как напиток и меч. Выпив некоего зелья, Зигмунд влюбляется в Зиглинду, Тристан - в Изольду. Мать в сказке Новалиса готовит напиток, который поможет восстановить равновесие в мире. Далее в произведениях двух авторов используется сюжетный мотив меча. Действие, проходившее в сказке Ф. Новалиса в высоких сферах, прерывается, 
когда старый Герой по имени Железо бросает свой меч в пространство и читатель переносится в другую сферу - дом, где подрастают молодые герои Эрот и Фабель. Эрот, получив от отца железный прут, быстро вырастает и отправляется в путешествие со своей крестной матерью Джиннистан. Вокруг меча Нотунга разворачивается множество событий в трех операх тетралогии - «Валькирии», «Зигфриде», «Гибели богов».

Проводя аналогии между приемами в конструировании мифов в произведениях Р. Вагнера и Ф. Новалиса, следует отметить использование сходных мифологических сюжетов. Так, в сказке Ф. Новалиса существует образная оппозиция Отец и Мать. Мужское начало - Отец рассматривается как сила, устремленная вовне (он приносит железный прут, способствующий возмужанию Эрота, уединяется с Джиннистан и т.д.), Мать областью своей деятельности имеет дом. В ней воплощено не только животворящее, но и жертвенное начало, гетевская «смерть для жизни новой». Мать сжигает себя на костре, чтобы напиток с ее пеплом способствовал наступлению вселенской гармонии. В этом сюжетном мотиве можно усмотреть сходство со сценой смерти Брунгильды и напитком любви-смерти из «Тристана и Изольды». Р. Вагнер в своих произведениях значительно перерабатывает не только мифологические сюжеты сказки Ф. Новалиса, но и общемировые мифологические сюжеты. Образы Отца и Матери относятся к архетипам мировой культуры. В произведениях Р. Вагнера активнодействующим началом является образ отца - Вотана, который представлен как сила, устремленная вовне, направленная на сохранение гармонии и расширение контролируемого пространства. Архетип матери в операх Р. Вагнера можно условно соотнести с образом Фрикки, которая близка по линии поведения образу древнегреческой ревнивой богини Геры. Таким образом, Р. Вагнер комбинирует сюжетные мифологические мотивы, создавая собственную мифологию. Его новый миф базируется на мифах народных и религиозных, такой интертекстуальный синтез сюжетов создает пример нового типа авторской мифологии. Такой тип синтеза становится моделью мифотворчества для композиторов, писателей, кинематографистов, мыслителей не только XIX, но и XX в.

За этими аналогиями скрывается не только логика конструирования мифа, но и единый для двух художников тип выражения мысли. Его можно назвать аллегорическим, символичным, метафоричным типом высказывания мысли. В этом смысле важно высказывание Ф. Новалиса, который утверждал: «Ничто не может быть противнее духу сказки, чем нравственный фатум, закономерная связь. В сказке царит подлинная природная анархия» [4. C. 637]. А в наброске к роману он предупреждал себя: «Только без строгой аллегории» [2. С. 393]. Простое аллегорическое истолкование действующих фигур не только обедняет, но и «трещит по швам» при чисто логической операции. Можно сказать, что и у Р. Вагнера, и Ф. Новалиса идея «всегда остается в образе бесконечно действенной и недостижимой».

\section{Литература}

1. Шеллинг Ф. Введение в философию мифологии [Электронный ресурс]. URL: filosof.historic.ru/books/item/foo/soo/zoooo446/st002.shtml (дата обращения: 30.05.2016). 
2. Ботникова А.Б. Немецкий романтизм : диалог художественных форм. М.: Аспект Пресс, 2005. 342 с. [Электронный ресурс]. URL: http://19v-euro-lit.niv.ru/19v-euro-lit/botnikovanemeckij-romantizm/skazka-klingsora-novalisa.htm (дата обращения: 30.05.2016).

3. Произведение искусства будущего // Вагнер Р. Избранные работы / сост. и коммент. И.А. Барсовой и С.А. Ошерова; вступ. ст. А.Ф. Лосева. М. : Искусство, 1978. С. 142-262.

4. Литературные манифесты западноевропейских романтиков / собр. текстов, вступ. ст.; общ. ред. А.С. Дмитриева. М. : Изд-во МГУ, 1980. 638 с.

Tashtamirova Liliy Sh. Tyumen State Institute of Culture (Tyumen, Russian Federation).

E-mail: varegka72@mail.ru

Tomsk State University Journal of Cultural Studies and Art History, 2017, № 25. 104- 112 pp.

DOI: $10.17223 / 22220836 / 25 / 13$

THE IMPACT ON THE WORK OF MYTH F. NOVALIS ON THE WORK OF R. WAGNER. A COMPARATIVE ANALYSIS OF THE WORKS.

Key words: R. Wagner, F. Novalis, opera librettos, a new mythology.

The problem of mythology, Wagner expounded in his literary works, it does not exhaust the whole problem of understanding and use of the myth of the composer. Libretto by Richard Wagner's operas provide ample material for research. In the research literature it remains an open question concerns the construction of a new mythology in the operas of Richard Wagner. In the study, we found a correlation between the literary works of the German Romantics and works of Richard Wagner. Significant analogies occur between the librettos of Wagner's operas and "Tales of Klingsor" from the novel "Heinrich von Ofterdingen" (1799) F. Novalis. We believe that, for Wagner, this work served as an example of the construction of the myth in his works. Artists drawn together not only the use of common methods in the construction and interpretation of the story, but also a common understanding of the goals and objectives of art. R. Wagner and F. Novalis were poets, not scientists or philosophers who adhere to the scientific approach to creating works of art. They learn about the world through the artistic sensibility and not by rational and logical. R. Wagner, based on the experience of German writers, and puts his characters in spaceless and timeless continuum. The specific historical time can be determined with a sufficient degree of conditionality - Middle Ages ("Lohengrin", "Tristan and Isolde"), the ancient world ("The Ring of the Nibelungs"). Moreover, it can be concluded that all time specification is impossible, since on closer examination Tannhäuser lives between two worlds - Catholic, where there is a Pope, pilgrims, Elizabeth, praying in a monastery for the soul of Tannhauser and Roman grotto of Venus, located outside time and space. R. Wagner, for his work unfolds the myth of the Knights of the Round Table, which is also in parallel a certain time and space. The use of this myth is a sacred Christian symbol, relevant to the present day, fills the works of the composer is not romantic fiction, but of religious mysticism. R. Wagner, based on specific legendary and mythological sources, combining them with the reception of the transcendental interpretation of the story, reaches in his works a new quality - support of opera scenes at the archetypes found Western culture. As a result, the composer superior achievements of literary romanticism in the way of creating a new mythology. Myths unfolding in the operas of Richard Wagner, creating a new way of communication with the listener, based on the appeal to the unconscious of the person receiving the top. This type of communication is not based on the direct verbal contact, and communicating through the actualization of cultural archetypes and cultural memory of the receiving side.

\section{References}

1. Shelling, F. (n.d.) Vvedenie v filosofiyu mifologii [Introduction to the philosophy of mythology]. [Online] Available from: filosof.historic.ru/books/item/foo/soo/zoooo446/st002.shtml. (Accessed: 30th May 2016).

2. Botnikova, A.B. (2005) Nemetskiy romantizm: dialog khudozhestvennykh form [German romanticism: The dialogue of artistic forms]. Moscow: Aspekt Press. [Online] Available from: http://19v-euro-lit.niv.ru/19v-euro-lit/botnikova-nemeckij-romantizm/skazka-klingsora-novalisa.htm. (Accessed: 30th May 2016).

3. Wagner, R. (1978) Izbrannye raboty [Selected Works]. Translated from German. Moscow: Iskusstvo. pp. 142-262.

4. Dmitriev, A.S. (ed.) (1980) Literaturnye manifesty zapadnoevropeyskikh romantikov [Literary Manifestoes of West European Romantics]. Moscow: Moscow State University. 